\title{
Geoquímica dos ortognaisses do Complexo Região dos Lagos, Araruama-Cabo Frio, Rio de Janeiro, Brasil
}

\author{
Samuel Magalhães Viana ${ }^{1}$, Claudia Sayão Valladares ${ }^{2} \&$ Beatriz Paschoal Duarte $^{2}$
}

\begin{abstract}
Resumo A área alvo da presente pesquisa localiza-se na porção centro-leste do estado do Rio de Janeiro, no Terreno Cabo Frio (TCF) inserida na extremidade sudeste da Faixa Ribeira. Esta corresponde a um cinturão NE-SW de empurrões e dobramentos brasilianos. Neste trabalho foram estudados ortognaisses que associados a ortoanfibolitos compõem o chamado Complexo Região dos Lagos (CRL), embasamento de idade paleoproterozóica do TCF. Trata-se de hornblenda-biotita gnaisse de composição predominantemente granodiorítica a monzogranítica, leucognaisse de composição sienogranítica e biotita gnaisse tonalítico e monzogranítico. As análises químicas revelam que tais ortognaisses são subalcalinos, cálcio-alcalinos e formam dois grupos marcantes: a) gnaisses de composição intermediária e teores de $\mathrm{K}_{2} \mathrm{O}$ mais baixos, abrangendo hornblenda-biotita gnaisse e biotita gnaisse, de composições variadas; b) gnaisses de composição ácida, com teores mais altos de $\mathrm{K}_{2} \mathrm{O}$, constituídos, em sua maioria, de leucognaisse granítico.A abordagem com base nos elementos terras raras (ETR) mostra que nem todas as amostras do CRL são cogenéticas, podendo haver até quatro suítes dentre as amostras estudadas. Os quatro agrupamentos identificados têm assinaturas geoquímicas semelhantes à de suítes geradas em ambientes tectônicos compressivos modernos. Especificamente, os ortognaisses do Complexo Região dos Lagos são interpretados como resultado de construção de arcos magmáticos mais maduros semelhantes aos granitos de arco vulcânico do Chile, gerados durante o Paleoproterozóico.
\end{abstract}

Palavras-chave: Faixa Ribeira, Terreno Cabo Frio, Complexo Região dos Lagos, Geoquímica dos ortognaisses.

\begin{abstract}
Geochemistry of orthogneisses of the Região dos Lagos Complex, Arararuama-Cabo Frio, Rio de Janeiro, Brazil. The study area is situated on the mid-east part of the Rio de Janeiro state, Brazil, in the Cabo Frio Terrane. This terrane is located on the southeastern extremity of the Ribeira belt, which corresponds to a NE-SW structure composed of thrusts and folds generated during the Brasiliano Orogeny. In this research, the units that constitute the basement of the Cabo Frio terrane, orthogneisses and orthoamphibolites of Região dos Lagos Complex, of Palaeoproterozoic age, were studied based on petrography and geochemistry of the orthogneisses. These are hornblende-biotite gneisses of granodioritic to monzogranitic composition, leucogneisses of granitic composition and biotite gneisses of tonalitic and monzogranitic composition. Chemical data reveal that the orthogneisses have a subalkaline, calc-alkaline character and can be divided into two groups: a) gneisses of intermediate composition and lower $\mathrm{K}_{2} \mathrm{O}$ values, covering hornblende-biotite gneisses and biotite gneisses of diverse compositions; b) gneisses of acid compositions and relatively higher $\mathrm{K}_{2} \mathrm{O}$ values, including, predominantly, the granitic leucogneiss. Rare earth element data indicate that not all the samples of the Região dos Lagos Complex are cogenetic, but four different suites can be considered. The four identified groups have geochemical signatures similar to the suites generated in modern compressive tectonic environments, particularly those from the volcanic arcs in Chile. The orthogneisses of the Região dos Lagos Complex are interpreted as the result of mature magmatic arc construction, generated during the Palaeoproterozoic.
\end{abstract}

Keywords: Ribeira belt, Cabo Frio Terrane, Região dos Lagos Complex, Geochemistry of orthogneisses.

INTRODUÇÃO O trabalho apresenta dados petrográficos e litogeoquímicos dos ortognaisses do Complexo Região dos Lagos (Fonseca, 1989), interpretado como embasamento paleoproterozóico do Terreno Cabo Frio (Heilbron et al., 2000).

A área estudada está limitada pelas coordenadas de $22^{\circ} 45^{\prime} \mathrm{S}$ e $23^{\circ} 00^{\prime} \mathrm{S}$ e $42^{\circ} 30^{\prime} \mathrm{W}$ e $41^{\circ} 45^{\prime} \mathrm{W}$, compreendendo a região entre Araruama e Cabo Frio (RJ) (Fig. 1), a cerca de $100 \mathrm{Km}$ a leste da cidade do Rio de Janeiro. A região geográfica, que deu o nome ao Complexo, é uma planície costeira constituída de restingas e bordejada por lagoas e lagunas, alinhadas segundo a direção leste-oeste. E limitada, a norte e noroeste, por serras de baixa altitude, com elevação máxima de $600 \mathrm{~m}$, e, a sul, pelo oceano Atlântico. Esta região difere topograficamente da região serrana (Serra dos Órgãos), a NNW, que

1 - Programa de Pós-Graduação em Análise de Bacias e Faixas Móveis, Faculdade de Geologia, Universidade do Estado do Rio de Janeiro (UERJ), Geólogo da PETROBRAS, Rio de Janeiro (RJ), Brasil. E-mail: viana.samuel@ig.com.br, samuel.viana@petrobras.com.br 2 - Departamento de Geologia Regional e Geotectônica, Faculdade de Geologia, Universidade do Estado do Rio de Janeiro (UERJ), Rio de Janeiro (RJ), Brasil. E-mail: vallada@uerj.br, biapasch@uerj.br 


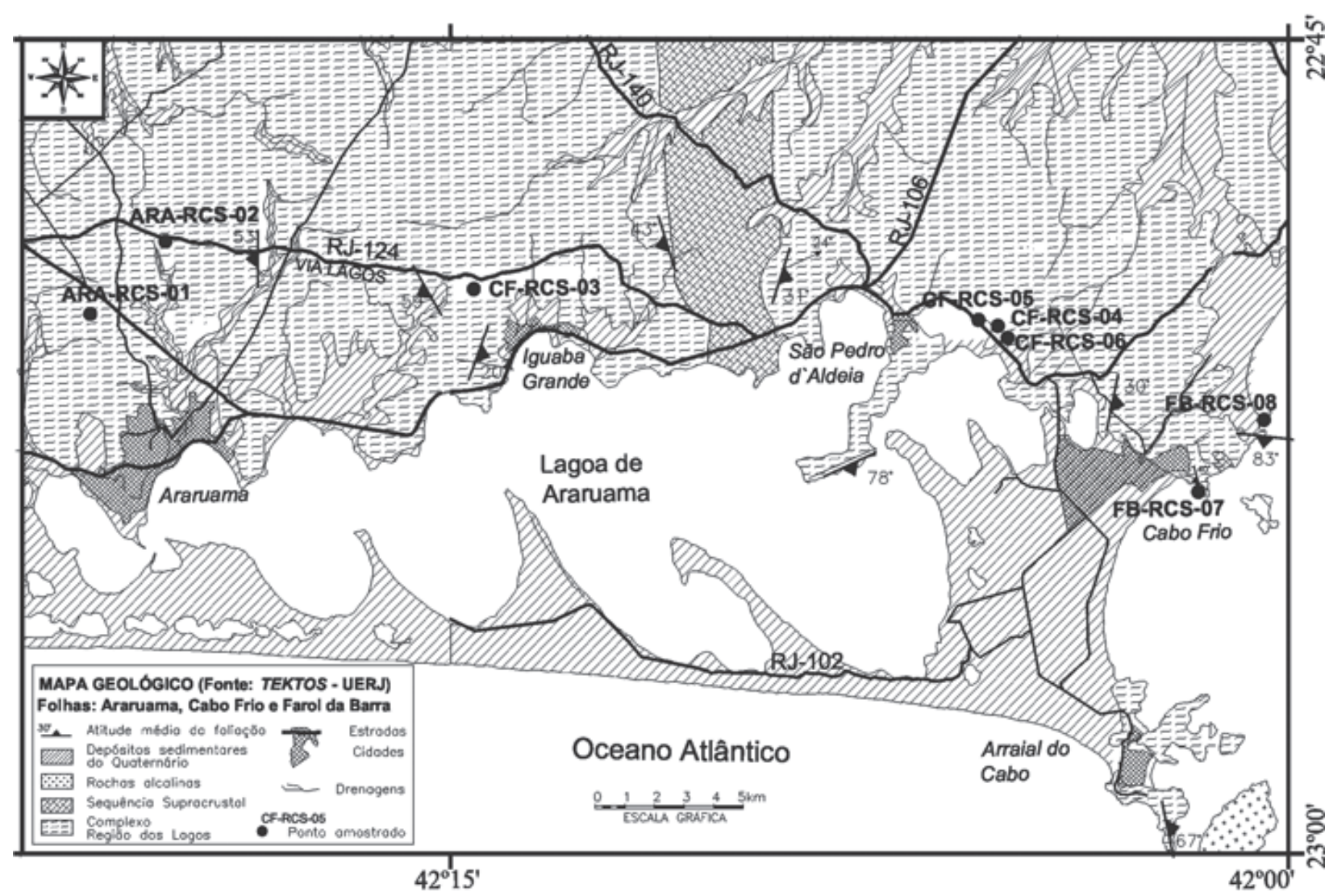

Figura 1 - Mapa geológico local e de localização dos pontos amostrados. Fonte: Grupo TEKTOS-UERJ, integração das Folhas Araruama, Cabo Frio e Farol da Barra, 1:50.000.

apresenta serras com altitudes muito mais elevadas com cristas alinhadas segundo a direção NE-SW.

CONTEXTO GEOLÓGICO A área de estudo está geotectonicamente inserida no contexto da Faixa Ribeira (Cordani et al., 1967, 1973; Almeida, 1967, 1969). Este cinturão brasiliano estende-se por $1400 \mathrm{Km}$ ao longo da região costeira atlântica do Brasil, desde o sul do estado da Bahia ao estado do Paraná. Compreende um complexo sistema de dobramentos e empurrões desenvolvidos durante um intervalo de 300 milhões de anos, do Neoproterozóico ao Eopaleozóico (Brito Neves e Cordani, 1991) ao longo da borda sul/sudeste do Cráton do São Francisco.

Heilbron et al. $(2000,2004)$ caracterizaram o segmento central da Faixa Ribeira como definido por quatro terrenos tectono-estratigráficos distintos. De NW para SE, esses terrenos são: a) o Terreno Ocidental que representa a margem retrabalhada do Cráton do São Francisco e inclui o Domínio Autóctone e os sistemas de empurrão Andrelândia e Juiz de Fora; b) O Terreno Paraíba do Sul que representa a escama de empurrão superior do segmento central da Faixa Ribeira; c) O Terreno Oriental, separado do Ocidental por uma importante zona de cisalhamento com mergulho moderado para NW (Limite Tectônico Central, Almeida et al., 1998), aloja o Arco Magmático Cordilheirano da Orogênese Ribeira (Complexo Rio Negro, Tupinambá et al., 1998, 2000); e d) o Terreno Cabo Frio, cujo embasamento é caracterizado pelo Complexo Região dos Lagos (Fonseca, 1989), foi estruturado durante os estágios terminais da colagem Brasiliana (Schmitt et al., 2004), com transporte para NW, representando assim, o terreno mais oriental do segmento central da Faixa Ribeira (Fig. 2).

O Complexo Região dos Lagos (Fonseca,1989) foi originalmente descrito como Unidade Região dos Lagos por Reis et al. (1980), tendo também recebido as designações de Sequência Inferior (Heilbron et al. 1982) e Unidade Gnáissico-Migmatítica (Fonseca e Silva, in Fonseca et al. 1984). É descrito na literatura como constituído por ortognaisses bandados/migmatíticos, cinzentos, de composição tonalítica a granítica, com predominância de composições graníticas, associados à corpos anfibolíticos variavelmente deformados (Heilbron et al. 1982, Fonseca et al., 1984, Fonseca et al., 1998, Schmitt et al., 2004). As primeiras datações de ortognaisses deste complexo foram produzidas por Zimbres et al. (1990) que obtiveram pelo método U-Pb em zircão a idade de $1981 \pm 18 \mathrm{Ma}$, considerada como idade de cristalização do protólito do ortognaisse. A idade de $488 \pm 55 \mathrm{Ma}$ (intercepto inferior) sugere, segundo os autores, uma perda episódica de $\mathrm{Pb}$ por parte dos cristais de zircão durante os eventos tectonomagmáticos finais do ciclo Brasiliano. Fonseca (1993) apresentou idades modelo TDM Sm-Nd dos ortognaisses entre 2663 e $2343 \mathrm{Ma}$, interpretando-as como época 


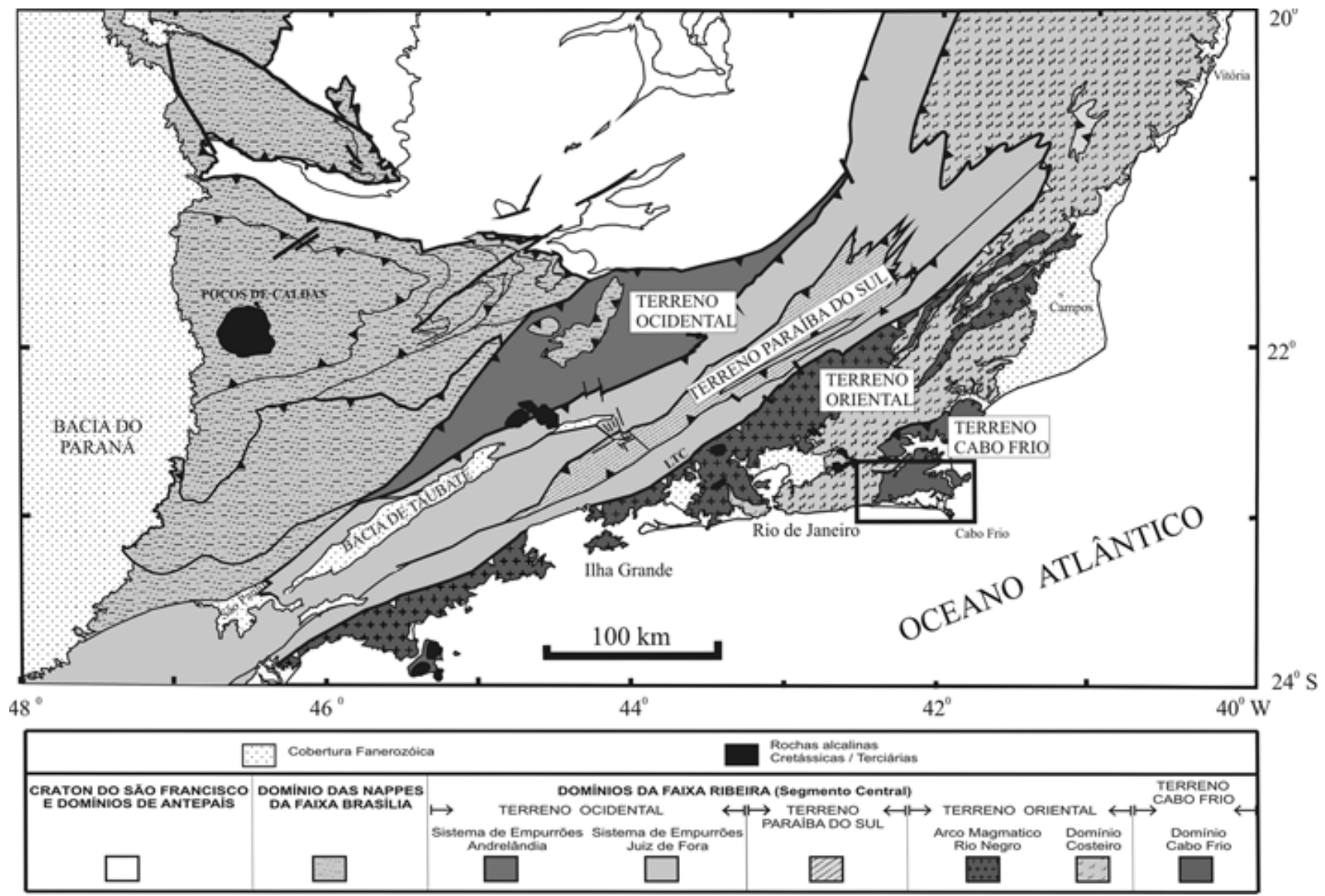

Figura 2 - Compartimentação tectônica da borda sul do Cráton do São Francisco (Heilbron et al., 1999a, 1999b). O retângulo em destaque no mapa corresponde a área de estudo, apresentada na figura 1.

máxima de formação de seus protólitos/fonte. A cristalização destas rochas durante o Paleoproterozóico foi confirmada por Schmitt et al. $(1999,2004)$ que obtiveram idades U-Pb em zircão de $1971 \pm 5$ Ma e $1960 \pm 6$ $\mathrm{Ma}$ (intercepto superior) e ca. 525-518 Ma (intercepto inferior e zircões de veios leucocráticos nos ortognaisses), essas últimas atribuídas ao retrabalhamento no Neoproterozóico.

\section{FEIÇÕES DE CAMPO E CARACTERÍSTICAS} PETROGRÁFICAS A área de ocorrência do Complexo Região dos Lagos é morfologicamente arrasada, constituindo uma planície litorânea com sedimentos marinhos quaternários cobrindo grande parte do terreno, o que resulta em afloramentos rochosos bastante esparsos.

As unidades litológicas que constituem o complexo foram agrupadas em dois conjuntos: ortognaisses e ortoanfibolitos.

Os ortognaisses, alvo das investigações petrográficas e litogeoquímicas abordadas neste artigo, têm maior distribuição espacial na região estudada e variações mineralógicas e texturais permitem subdividí-los em três subtipos: hornblenda-biotita gnaisse, leucognaisse e biotita gnaisse (Tab. 1).

O hornblenda-biotita gnaisse é o litotipo de maior predomínio dentro do complexo, e ocorre intercalado com o biotita gnaisse, em menor proporção, apresentando contatos gradacionais e paralelos à foliação tectônica. Alguns leucognaisses apresentam contatos gradacionais com os demais gnaisses, porém foram identificados corpos lenticulares métricos de contato bem definido, também paralelo à foliação. Pode-se especular que a origem de alguns leucognaisses estaria relacionada a uma granitogênese brasiliana.

A paragênese mineral mostra que os ortognaisses do Complexo Região dos Lagos foram metamorfisados sob condições da fácies anfibolito superior. Estudos geocronológicos de Fonseca (1993) e Schmitt (2001) confirmaram evento metamórfico no Cambriano Médio que, tendo promovido anatexia nas rochas, produziu migmatização em diferentes intensidades.

Os ortoanfibolitos ocorrem como corpos de dimensões métricas a decimétricas dentro dos ortognaisses. Estes corpos apresentam-se em camadas lenticulares paralelas à foliação, enclaves, boudins ou corpos tabulares interpretados como paleodiques. Os ortoanfibolitos foram denominados por Schmitt et al. (2004) como Unidade Forte São Mateus.

Hornblenda-biotita gnaisse Consiste de um ortognaisse granoblástico inequigranular, de variadas proporções plagioclásio/microclina. Sua granulação é média a grossa e sua textura é porfiroblástica. Este litotipo é o mais comum na área estudada e aflora ao longo da Via 
Tabela 1 - Relação das amostras do Complexo Região dos Lagos selecionadas para o estudo.

\begin{tabular}{|c|c|c|c|c|}
\hline \multirow{2}{*}{ Ponto } & \multicolumn{2}{|c|}{ Coordenadas } & \multirow{2}{*}{ Amostras } & \multirow{2}{*}{ Tipo petrográfico } \\
\hline & $\mathrm{N}$ & $\mathrm{E}$ & & \\
\hline 1 - Pedreira de Araruama & 7472563 & 770250 & ARA-RCS-01 & Biotita Gnaisse * \\
\hline 2 - Km 35 da Via Lagos-RJ & 7475012 & 772783 & ARA-RCS-02 B & Hbl-Bt Gnaisse * \\
\hline 3 - Km 46 da Via Lagos-RJ & 7473401 & 783197 & CF-RCS-03 B & Hbl-Bt Gnaisse * \\
\hline \multirow{2}{*}{4 - Pedreira abandonada - São Pedro d'Aldeia } & \multirow{2}{*}{7472157} & \multirow{2}{*}{800901} & CF-RCS-04 A & Leucognaisse * \\
\hline & & & CF-RCS-04 C & Leucognaisse \\
\hline \multirow{2}{*}{$\begin{array}{l}5 \text {-Pedreira abandonada- Morro dos Milagres } \\
\text { - São Pedro d'Aldeia }\end{array}$} & \multirow[t]{2}{*}{7472361} & \multirow[t]{2}{*}{800245} & CF-RCS-05 A & Leucognaisse * \\
\hline & & & CF-RCS-05 C & Leucognaisse * \\
\hline \multirow{4}{*}{$\begin{array}{l}6 \text { - Pedreira Campo Redondo- Morro do } \\
\text { Frade-São Pedro d'Aldeia }\end{array}$} & \multirow{4}{*}{7471759} & \multirow{4}{*}{801231} & CF-RCS-06 A & Hbl-Bt Gnaisse * \\
\hline & & & CF-RCS-06 B & Biotita Gnaisse * \\
\hline & & & CF-RCS-06 C & Leucognaisse * \\
\hline & & & CF-RCS-06 D & Hbl-Bt Gnaisse * \\
\hline 7- Praia do Forte São Mateus- Cabo Frio & 7466550 & 807669 & FB-SC-07C & Biotita gnaisse \\
\hline \multirow{3}{*}{8 - Praia das Conchas- Cabo Frio } & \multirow{3}{*}{7468984} & \multirow{3}{*}{809885} & FB-SC-08 A & Hbl-Bt Gnaisse \\
\hline & & & FB-SC-08 B & Hbl-Bt Gnaisse \\
\hline & & & FB-SC-08 E & Hbl-Bt Gnaisse \\
\hline
\end{tabular}

* amostras com análise química (dados na Tab. 2).

Lagos-RJ, nas pedreiras próximas a São Pedro d' Aldeia e na praia das Conchas em Cabo Frio (Fig. 1, Tab. 1). Apresenta coloração cinza escura e nítida orientação mineral preferencial formando lineação (dada por cristais de feldspato e hornblenda), e foliação (marcada pelas plaquetas de biotita). Ao longo da Via Lagos-RJ, estas rochas apresentam "clots" de hornblenda, de até $2 \mathrm{~cm}$, textura granoblástica e estrutura maciça. Na Praia das Conchas, o horblenda-biotita gnaisse apresenta-se menos deformado, sendo observados megacristais euédricos de microclina, interpretados como fenocristais reliquiares.

Tais rochas apresentam uma relativa variedade composicional. Apesar da maior parte possuir composição entre granodiorito e monzogranito (Fig. 3), ocorrem também sienogranito e quartzo-sienito, segundo a classificação de Streckeisen (1976).

$\mathrm{Na}$ análise microscópica, este subgrupo revela grãos félsicos anédricos e fraturados, por vezes com extinção ondulante e recristalizados nos setores mais deformados. Apresenta, em geral, maior proporção de plagioclásio (28-50\%) em relação à microclina (10$28 \%$ ), excluindo-se o sienogranito e o quartzo-sienito. O plagioclásio é oligoclásio e seus grãos são anédricos, com geminações polissintéticas bem definidas havendo indícios de sericitização em fraturas e bordas. Grãos de quartzo (15-32\%) anédricos e recristalizados apresentam, comumente, extinção ondulante. Os grãos de microclina são anédricos, pertíticos a micropertíticos. Os minerais máficos, representados por hornblenda (5-12\%) e biotita (3-12\%), apresentam, em geral, proporções equilibradas. A hornblenda ocorre em grãos anédricos e fraturados, por vezes parcialmente cloritizados. A biotita é verde pálida e ocorre em curtas plaquetas, parcialmente cloritizadas, definindo a xistosidade da rocha. Como acessórios, ocorrem titanita euédrica, apatita e zircão inclusos em quartzo, plagioclásio e microclina, e magnetita. Como minerais secundários são comuns sericita, carbonato e óxido/hidróxido de ferro, além de clorita.

Leucognaisse Consiste de um ortognaisse leucocrático a hololeucocrático, granoblástico, maciço, de granulação média, encontrado, por exemplo, na pedreira Campo Redondo e no Morro dos Milagres (Tab. 1), pontos localizados a ca. de $3 \mathrm{~km}$ do município de São Pedro d'Aldeia. Este subtipo apresenta composição sieno-granítica (Fig. 3).

$\mathrm{Na}$ análise microscópica, o leucognaisse revela grãos félsicos anédricos e fraturados, por vezes com extinção ondulante ou recristalizados. Apresenta grande proporção de microclina (40 a $68 \%$ ), por vezes pertítica a micropertítica, comumente sericitizada. Grãos de quartzo anédricos constituem de 20 a $38 \%$ do volume 


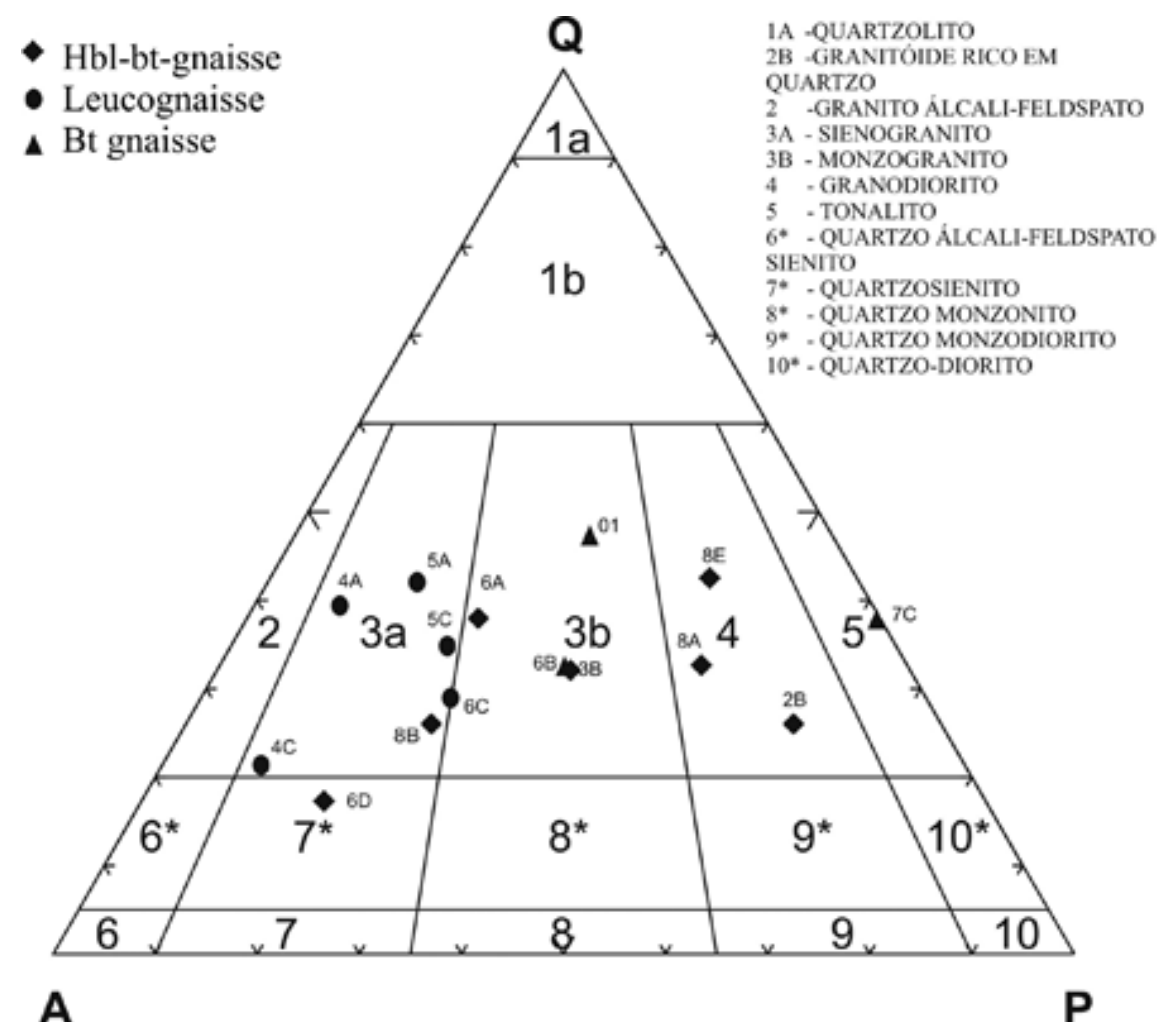

Figura 3 - Classificação petrográfica dos ortognaisses do Complexo Região dos Lagos, segundo Streckeisen (1976).

da rocha e apresentam comumente extinção ondulante. O plagioclásio (oligoclásio), que perfaz de 9 a $22 \%$ do volume da rocha, ocorre em grãos parcialmente sericitizados, ao longo de bordas e fraturas. Os minerais máficos são representados por biotita e hornblenda $(<6 \%)$, com predominância da primeira. A hornblenda ocorre em grãos anédricos e fraturados, por vezes parcialmente cloritizada. Como acessórios, foram identificados titanita, apatita e zircão, os dois últimos como inclusões em quartzo e feldspatos.

Biotita gnaisse Consiste de um ortognaisse granoblástico de granulação média a grossa, em geral, com maior proporção de plágioclásio em relação ao feldspato alcalino. Grãos de biotita compõem a fase máfica principal. Esse litotipo ocorre na Pedreira de Araruama, na Pedreira Campo Redondo (São Pedro d'Aldeia), e na Praia do Forte (Cabo Frio) (Tab. 1, Fig. 1). Tem composição monzogranítica, com exceção de uma amostra (FB-SC-07C), cuja composição é tonalítica (Fig. 3).

Os grãos de quartzo (31-42\%) são anédricos, fraturados, com extinção ondulante e, por vezes, recristalizados. O plagioclásio (25-52\%) é do tipo oligoclásio, anédrico a subédrico, com geminação polissintética, por vezes em duas direções. A microclina (20-32\%) ocorre em grãos anédricos a subédricos, geminados e parcialmente sericitizados. A fase máfica é representada por biotita (4-17\%), de pleocroísmo ocre, que ocorre em plaquetas subédricas curtas a alongadas, orientadas na foliação da rocha. Dentre os acessórios mais comuns estão hornblenda, titanita, apatita e zircão. Carbonato, sericita e óxido de ferro são as fases minerais secundárias.

\section{GEOQUÍMICA DOS ORTOGNAISSES DO COM- PLEXO REGIÃO DOS LAGOS Com o intuito} de caracterizar geoquimicamente os ortognaisses do Complexo Região dos Lagos foram realizadas dez análises químicas de rocha total (elementos maiores e traços, incluindo os terras raras), englobando os três tipos petrográficos identificados (Tab. 1). Foram selecionadas para este estudo afloramentos localizadas em pedreiras e corte de estradas, e evitados aqueles de costões rochosos em praias. Foram também evitadas as amostras afetadas por migmatização e/ou deformação intensa. As análises químicas foram efetuadas por ICP-AES e ICP-MS no Activation Laboratories, ACTLABS, no Canadá.

Das dez amostras selecionadas para geoquímica, quatro são de hornblenda-biotita-gnaisse, duas de biotita-gnaisse, e quatro de leucognaisse. Os dados geoquímicos (Tab. 2) e petrográficos integrados indicam que o hornblenda-biotita gnaisse é constituído predominantemente de rochas intermediárias $\left(\mathrm{SiO}_{2}\right.$ entre 61 e $65 \%$ ), enquanto que o biotita-gnaisse e o leucognaisse constituem rochas ácidas $\left(\mathrm{SiO}_{2}\right.$ entre 65 e 75\%). Os baixos valores de $L O I$ e os resultados analíticos não revelaram problemas nos valores ou correlações que pudessem indicar processos metassomáticos.

Geoquímica dos elementos maiores São ainda escassos os estudos de cunho petrológico dos ortognais- 
Tabela 2 - Dados litogeoquímicos inéditos dos ortognaisses do Complexo Região dos Lagos.

\begin{tabular}{|c|c|c|c|c|c|c|c|c|c|c|c|}
\hline & & \multicolumn{3}{|c|}{ hbl-bt gnaisse } & \multicolumn{2}{|c|}{ bt gnaisse } & \multirow{2}{*}{$\begin{array}{c}\text { hbl-bt- } \\
\text { gnais. } \\
\text { CF RCS } \\
\text { 03B }\end{array}$} & \multicolumn{4}{|c|}{ leucognaisse } \\
\hline & & $\begin{array}{c}\text { CF RCS } \\
06 \mathrm{D}\end{array}$ & $\begin{array}{c}\text { ARA } \\
\text { RCS 02B }\end{array}$ & $\begin{array}{c}\text { CF RCS } \\
06 \mathrm{~A}\end{array}$ & $\begin{array}{c}\text { ARA } \\
\text { RCS } 01\end{array}$ & $\begin{array}{c}\text { CF RCS } \\
06 \mathrm{~B}\end{array}$ & & $\begin{array}{c}\text { CF RCS } \\
04 \mathrm{~A}\end{array}$ & $\begin{array}{c}\text { CF RCS } \\
05 \mathrm{~A}\end{array}$ & $\begin{array}{c}\text { CF RCS } \\
\text { 06C }\end{array}$ & $\begin{array}{c}\text { CF RCS } \\
05 \mathrm{C}\end{array}$ \\
\hline $\mathrm{SiO}_{2}$ & $\%$ & 61,11 & 62,25 & 64,31 & 64,82 & 67,91 & 69,96 & 70,59 & 70,95 & 71,44 & 74,26 \\
\hline $\mathrm{Al}_{2} \mathrm{O}_{3}$ & $\%$ & 15,91 & 16,73 & 15,57 & 16,67 & 14,92 & 14,76 & 14,98 & 14,59 & 14,69 & 13,25 \\
\hline $\mathrm{Fe}_{2} \mathrm{O}_{3}$ & $\%$ & 7,08 & 5,34 & 5,61 & 4,44 & 4,4 & 2,88 & 2,12 & 2,59 & 2,17 & 1,81 \\
\hline $\mathrm{MnO}$ & $\%$ & 0,178 & 0,101 & 0,122 & 0,066 & 0,119 & 0,047 & 0,028 & 0,049 & 0,036 & 0,027 \\
\hline $\mathrm{MgO}$ & $\%$ & 1,76 & 2,2 & 1,47 & 1,6 & 1,16 & 0,85 & 0,52 & 0,72 & 0,47 & 0,27 \\
\hline $\mathrm{CaO}$ & $\%$ & 4,68 & 4,36 & 3,95 & 3,63 & 3,15 & 2,3 & 2,07 & 2,29 & 2,38 & 1,84 \\
\hline $\mathrm{Na}_{2} \mathrm{O}$ & $\%$ & 4,08 & 4,49 & 4,16 & 5 & 4,16 & 3,43 & 3,67 & 3,5 & 3,67 & 3,07 \\
\hline $\mathrm{K}_{2} \mathrm{O}$ & $\%$ & 3,63 & 2,98 & 3,18 & 2,25 & 2,98 & 4,57 & 5,11 & 4,73 & 4,48 & 4,96 \\
\hline $\mathrm{TiO}_{2}$ & $\%$ & 1,057 & 0,695 & 0,882 & 0,695 & 0,696 & 0,343 & 0,399 & 0,34 & 0,335 & 0,257 \\
\hline $\mathrm{P}_{2} \mathrm{O}_{5}$ & $\%$ & 0,32 & 0,23 & 0,25 & 0,23 & 0,2 & 0,12 & 0,09 & 0,1 & 0,06 & 0,05 \\
\hline LOI & $\%$ & 0,44 & 0,32 & 0,44 & 0,37 & 0,39 & 0,34 & 0,55 & 0,2 & 0,28 & 0,36 \\
\hline TOTAL & $\%$ & 100,23 & 99,69 & 99,94 & 99,77 & 100,08 & 99,61 & 100,11 & 100,07 & 100 & 100,15 \\
\hline $\mathrm{V}$ & ppm & 65,22 & 85,03 & 72,90 & 63,67 & 48,85 & 34,51 & 25,38 & 31,83 & 14,46 & 14,81 \\
\hline $\mathrm{Cr}$ & $\mathrm{ppm}$ & nd & 26,01 & nd & nd & nd & nd & nd & nd & nd & nd \\
\hline Co & ppm & 8,98 & 14,11 & 10,06 & 11,04 & 7,94 & 4,74 & 2,93 & 4,17 & 2,52 & 1,42 \\
\hline $\mathrm{Ni}$ & ppm & nd & 33,92 & 43,87 & nd & nd & nd & nd & nd & nd & nd \\
\hline $\mathrm{Cu}$ & $\mathrm{ppm}$ & 30,83 & 48,71 & 49,06 & 24,33 & 19,07 & nd & nd & nd & nd & nd \\
\hline $\mathrm{Zn}$ & ppm & 93,45 & 80,52 & 86,50 & 60,63 & 58,98 & 32,01 & 33,68 & 37,35 & nd & nd \\
\hline $\mathrm{Ga}$ & ppm & 18,52 & 24,29 & 20,14 & 25,22 & 18,55 & 14,94 & 16,75 & 17,58 & 15,98 & 13,86 \\
\hline $\mathrm{Ge}$ & $\mathrm{ppm}$ & 1,20 & 1,35 & 1,22 & 1,12 & nd & nd & 1,02 & 1,18 & nd & 1,77 \\
\hline $\mathrm{Rb}$ & ppm & 51,60 & 130,28 & 70,91 & 86,32 & 78,28 & 68,38 & 95,60 & 105,25 & 79,95 & 84,02 \\
\hline $\mathrm{Sr}$ & ppm & 356,55 & 373,84 & 418,10 & 613,90 & 359,24 & 447,56 & 480,97 & 446,10 & 412,38 & 405,55 \\
\hline $\mathrm{Y}$ & $\mathrm{ppm}$ & 43,65 & 31,48 & 24,60 & 15,05 & 23,99 & 6,88 & 11,17 & 18,75 & 10,87 & 11,58 \\
\hline $\mathrm{Zr}$ & ppm & 267,29 & 270,30 & 227,38 & 359,55 & 200,98 & 126,93 & 265,02 & 196,03 & 144,08 & 184,05 \\
\hline $\mathrm{Nb}$ & ppm & 14,67 & 20,18 & 10,91 & 14,05 & 10,63 & 5,36 & 7,07 & 11,18 & 6,38 & 7,49 \\
\hline Sn & $\mathrm{ppm}$ & 3,66 & 5,02 & 3,13 & 1,81 & 1,64 & nd & 1,46 & 2,04 & 1,17 & 1,07 \\
\hline Cs & ppm & nd & 1,81 & 0,96 & 0,59 & 1,19 & nd & 1,01 & 0,91 & 0,58 & 0,96 \\
\hline $\mathrm{Ba}$ & ppm & 1110,00 & 420,74 & 1200,00 & 547,46 & 936,97 & 1230,00 & 1830,00 & 1520,00 & 1420,00 & 1440,00 \\
\hline $\mathrm{Hf}$ & ppm & 6,61 & 6,70 & 5,40 & 8,75 & 4,70 & 3,05 & 6,30 & 4,56 & 3,75 & 5,23 \\
\hline $\mathrm{Ta}$ & ppm & 1,08 & 1,65 & 0,62 & 0,88 & 0,87 & 0,22 & 0,51 & 0,84 & 0,43 & 0,69 \\
\hline $\mathrm{Tl}$ & ppm & 0,21 & 0,52 & 0,29 & 0,29 & 0,27 & 0,19 & 0,38 & 0,30 & 0,24 & 0,45 \\
\hline $\mathrm{Pb}$ & ppm & 15,34 & 15,58 & 17,54 & 8,64 & 15,42 & 10,80 & 24,39 & 16,82 & 11,40 & 18,78 \\
\hline Th & ppm & 16,48 & 24,72 & 11,12 & 30,06 & 13,73 & 13,26 & 21,45 & 17,09 & 18,71 & 15,72 \\
\hline $\mathrm{U}$ & ppm & 1,23 & 3,09 & 1,39 & 1,21 & 2,64 & 0,47 & 1,01 & 1,36 & 0,78 & 0,96 \\
\hline $\mathrm{La}$ & ppm & 45,06 & 68,75 & 46,90 & 111,30 & 36,30 & 80,82 & 73,98 & 43,97 & 67,58 & 38,76 \\
\hline $\mathrm{Ce}$ & ppm & 82,55 & 127,12 & 82,04 & 202,26 & 66,25 & 141,23 & 131,03 & 81,85 & 109,93 & 73,83 \\
\hline $\operatorname{Pr}$ & ppm & 9,13 & 13,58 & 8,76 & 20,76 & 6,97 & 13,88 & 13,75 & 8,66 & 10,03 & 8,05 \\
\hline $\mathrm{Nd}$ & ppm & 38,01 & 50,38 & 35,44 & 73,96 & 27,24 & 47,66 & 49,38 & 32,32 & 33,09 & 31,61 \\
\hline $\mathrm{Sm}$ & ppm & 7,76 & 8,12 & 6,20 & 9,74 & 4,65 & 5,51 & 7,24 & 4,95 & 3,98 & 5,04 \\
\hline $\mathrm{Eu}$ & $\mathrm{ppm}$ & 1,90 & 1,21 & 1,71 & 1,84 & 1,31 & 1,09 & 1,38 & 1,10 & 0,97 & 1,07 \\
\hline $\mathrm{Gd}$ & $\mathrm{ppm}$ & 6,98 & 5,64 & 4,68 & 5,33 & 3,67 & 3,00 & 4,48 & 3,15 & 2,46 & 3,11 \\
\hline $\mathrm{Tb}$ & ppm & 1,31 & 0,87 & 0,78 & 0,62 & 0,62 & 0,32 & 0,57 & 0,47 & 0,38 & 0,43 \\
\hline Dy & ppm & 8,03 & 4,82 & 4,55 & 2,98 & 3,88 & 1,50 & 2,64 & 2,74 & 1,95 & 2,23 \\
\hline Ho & $\mathrm{ppm}$ & 1,63 & 0,99 & 0,89 & 0,51 & 0,86 & 0,25 & 0,41 & 0,59 & 0,38 & 0,41 \\
\hline $\mathrm{Er}$ & ppm & 4,81 & 3,20 & 2,64 & 1,50 & 2,94 & 0,73 & 1,14 & 1,99 & 1,14 & 1,33 \\
\hline $\mathrm{Tm}$ & $\mathrm{ppm}$ & 0,71 & 0,57 & 0,36 & 0,20 & 0,51 & 0,09 & 0,13 & 0,35 & 0,15 & 0,20 \\
\hline $\mathrm{Yb}$ & $\mathrm{ppm}$ & 4,14 & 3,74 & 2,22 & 1,31 & 3,42 & 0,53 & 0,80 & 2,41 & 0,97 & 1,29 \\
\hline $\mathrm{Lu}$ & $\mathrm{ppm}$ & 0,56 & 0,57 & 0,32 & 0,20 & 0,56 & 0,07 & 0,10 & 0,36 & 0,13 & 0,19 \\
\hline $\mathrm{Yb}_{\mathrm{N}}$ & & 19,76 & 17,86 & 10,58 & 6,25 & 16,31 & 2,53 & 3,8199 & 11,49 & 4,64 & 6,14 \\
\hline$L a_{N}$ & & 145,36 & 221,77 & 151,30 & 359,02 & 117,10 & 260,70 & 238,63 & 141,83 & 217,99 & 125,03 \\
\hline$(\mathrm{La} / \mathrm{Yb})_{\mathrm{N}}$ & & 7,36 & 12,42 & 14,30 & 57,47 & 7,18 & 103,24 & 62,64 & 12,35 & 46,97 & 20,36 \\
\hline$(\mathrm{La} / \mathrm{Sm})_{\mathrm{N}}$ & & 3,65 & 5,32 & 4,76 & 7,19 & 4,91 & 9,23 & 6,42 & 5,59 & 10,67 & 4,84 \\
\hline$(\mathrm{Sm} / \mathrm{Lu})_{\mathrm{N}}$ & & 2,31 & 2,35 & 3,18 & 8,16 & 1,38 & 12,92 & 11,81 & 2,29 & 4,91 & 4,49 \\
\hline Eu/Eu* & & 0,79 & 0,54 & 0,97 & 0,78 & 0,96 & 0,82 & 0,74 & 0,85 & 0,94 & 0,82 \\
\hline
\end{tabular}


ses do Complexo Região dos Lagos. Fonseca (1993), interpretando dados de elementos maiores de três amostras, concluiu que estas rochas pertencem a uma série metaluminosa cálcioalcalina de alto-K. Viana (2003) apresentou novos dados litogeoquímicos agora disponibilizados no presente artigo.

Os ortognaisses do Complexo Região dos Lagos têm composição sienogranítica/monzogranítica e granodiorítica, com tonalitos subordinados, e pertencem à série calcioalcalina de caráter metaluminoso (Fig. 4). Pode-se observar a existência de dois agrupamentos, com cinco amostras cada um: A) um grupo constituído de hornblenda-biotita gnaisses e biotita gnaisses, de caráter metaluminoso mais forte e menores teores de $\mathrm{SiO}_{2}$ e $\mathrm{K}_{2} \mathrm{O}$, referente às rochas intermediárias (série calcioalcalina de médio a alto-K); e B) grupo constituído de hornblenda-biotita gnaisse ácido e leucognaisses, de caráter metaluminoso mais fraco e maiores teores de $\mathrm{SiO}_{2}$ e $\mathrm{K}_{2} \mathrm{O}$, referente às rochas mais ácidas (série calcioalcalina de alto-K).
A partir da análise dos diagramas de variação de Harker (Fig. 5), com materialização de duas linhas de tendência (uma linear e outra polinomial), foram obtidos coeficientes de correlação $\mathrm{R}^{2}$ para as amostras estudadas (Fig. 5A, Tab.3).

Verifica-se, através dos gráficos e valores de $\mathrm{R}^{2}$ que, no geral, as correlações são muito boas, com alto percentual de significância. $\mathrm{O}$ nível de significância de ambas as correlações são idênticos, com exceção de $\mathrm{Na}_{2} \mathrm{O}$ e $\mathrm{K}_{2} \mathrm{O}$. Nestes casos, deve-se considerar a correlação linear como a mais adequada, visto ter esta caráter mais específico.

Geoquímica dos elementos traços Dando prosseguimento à análise dos diagramas de Harker para os ortognaisses estudados, foram selecionados elementos traços com as seguintes características: dois elementos compatíveis ( $\mathrm{V}$ e $\mathrm{Co}$ ); dois elementos incompatíveis imóveis ( $\mathrm{Zr}$ e $\mathrm{Nb})$; e dois elementos incompatíveis móveis ( $\mathrm{Ba}$ e $\mathrm{Rb}$ ). As amostras foram plotadas para os referidos diagramas (Fig. 5B), seguindo os mesmos cri-
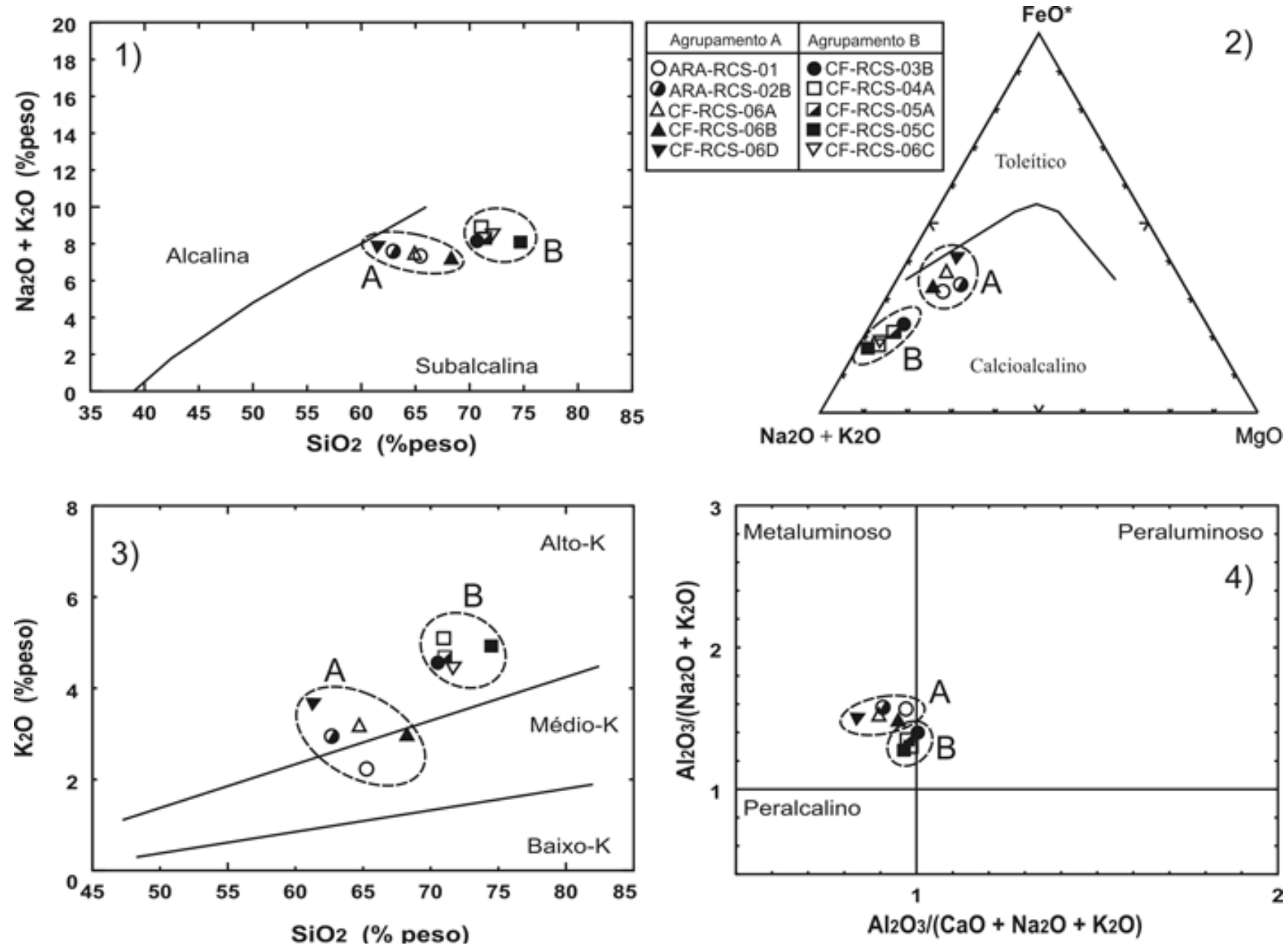

Figura 4 - Diagramas classificatórios utilizados para elementos maiores dos ortognaisses do Complexo Região dos lagos. 1) Diagrama sílica x álcalis com o limite entre os campos alcalino e subalcalino segundo Irvine \& Baragar (1971). 2) Diagrama AFM com limite entre os campos calcioalcalino e tholeiítico segundo Irvine \& Baragar (1971). 3) Diagrama $\mathrm{K}_{2} \mathrm{O} \times \mathrm{SiO}_{2}$, com limites extraídos de Le Maitre (1989). 4) Caráter metaluminoso dos ortognaisses do Complexo Região dos Lagos, com índice de Shand inferior a 1,0, segundo Maniar \& Piccoli (1989). 

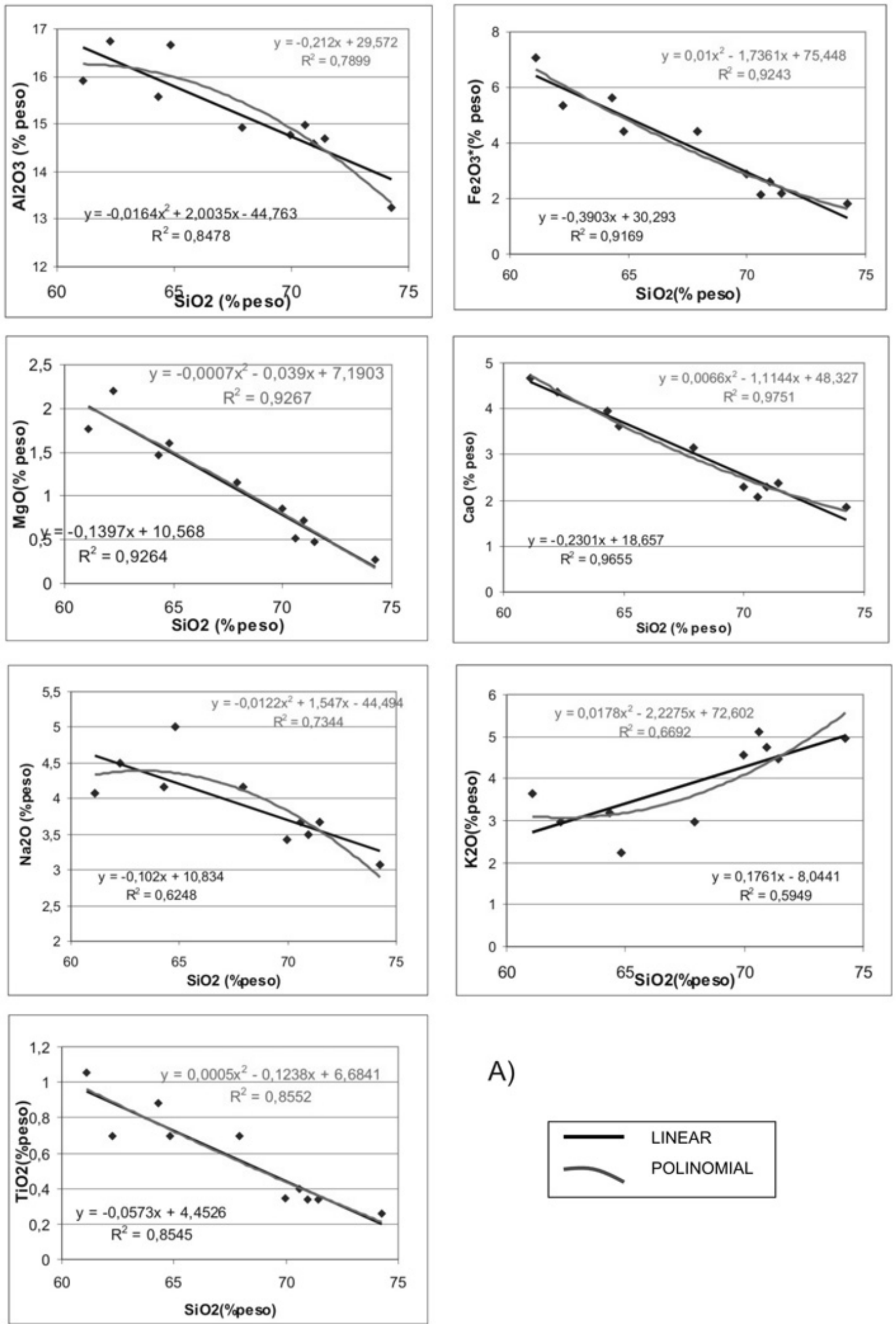

A)

Figura 5 A - Diagramas de Harker (elementos maiores) para todo o conjunto de ortognaisses analisados do Complexo Região dos Lagos. 

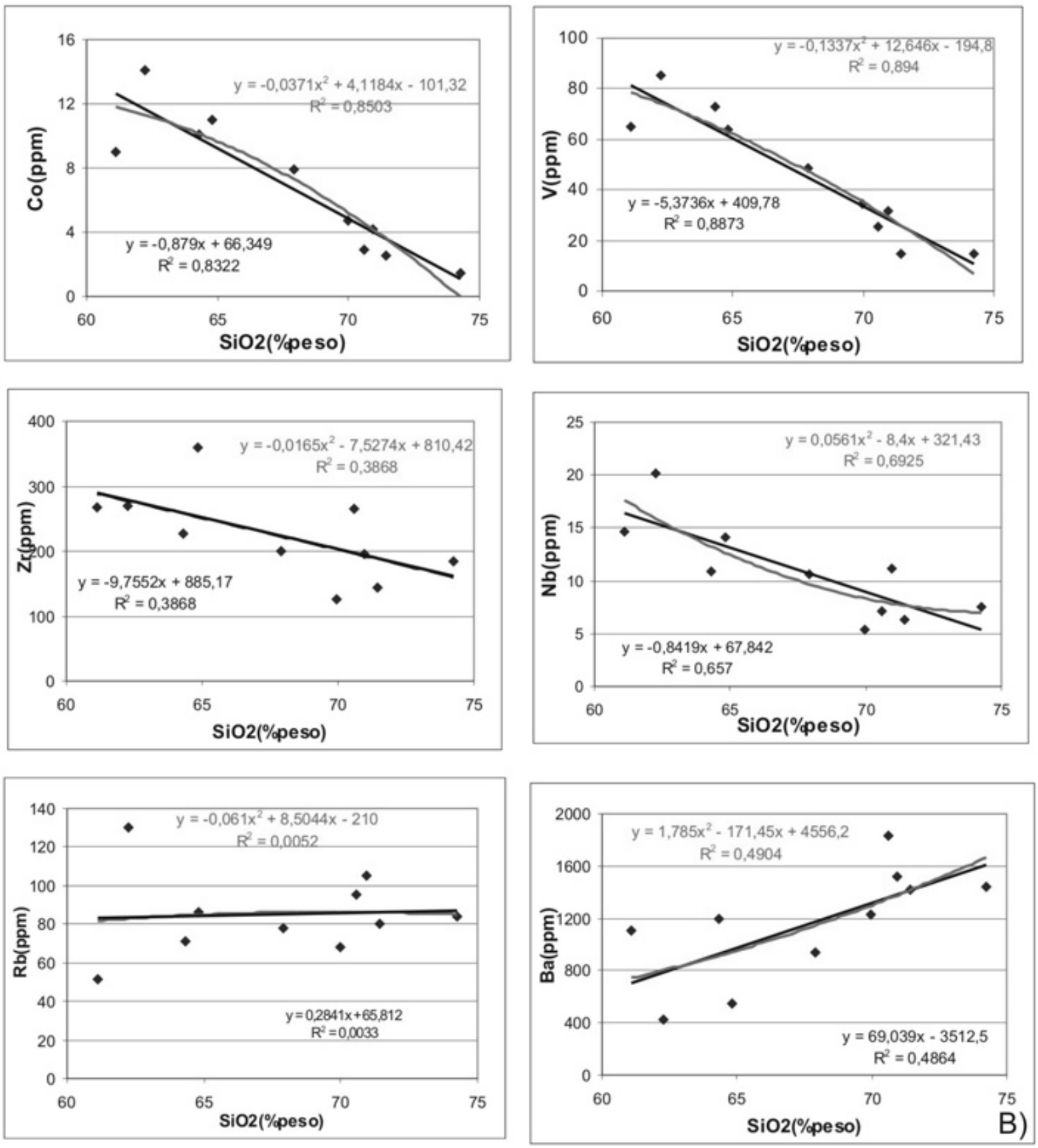

Figura 5B - Diagramas de Harker (elementos traços) para todo o conjunto de ortognaisses analisados do Complexo Região dos Lagos.

térios utilizados para os elementos maiores.

$\mathrm{Na}$ análise dos diagramas, observa-se que, assim como ocorrem para os elementos maiores, as correlações polinomiais apresentam valores de R2 mais elevados e mesmo nível de significância que as lineares (Tab. 3). Novamente, deve-se optar pela correlação linear.

As correlações lineares são características de processos como mistura magmática, assimilação simples e cristalização fracionada sem mudança na assembléia fracionante. No entanto, nos casos de mistura magmática e assimilação simples são comuns lacunas composicionais nos diagramas de variação tipo Harker, o que não é observado no conjunto de amostras estudadas. Além disso, o processo de mistura magmática envolve magmas de composições contrastantes, o que não é o caso para as rochas estudadas, uma vez que tratam-se de rochas de composições similares. O processo de assimilação simples no caso de rochas plutônicas é normalmente acompanhado por processo de cristalização fracionada, portanto, assimilação pura e simples pode também ser descartada como processo evolutivo dominante. A hipótese mais provável para traduzir o processo evolutivo do conjunto estudado é o processo de cristalização fracionada sem mudança da assembléia 
Tabela 3 - Valores dos coeficientes de correlação $R^{2}$ obtidos por regressão, e seus respectivos niveis de significância, para os elementos maiores e traços dos ortognaisses do Complexo Região dos Lagos.

\begin{tabular}{|c|c|c|c|c|}
\hline \multicolumn{5}{|c|}{ Elementos maiores } \\
\hline & \multicolumn{2}{|r|}{ Linear } & \multicolumn{2}{|c|}{ Polinômio } \\
\hline & $\mathrm{R}^{2}$ & \% Significância & $\mathrm{R}^{2}$ & \% Significância \\
\hline $\mathrm{Al}_{2} \mathrm{O}_{3}$ & 0,7899 & $99-99,9$ & 0,8478 & $99-99,9$ \\
\hline $\mathrm{Fe}_{2} \mathrm{O}_{3}{ }^{\mathrm{T}}$ & 0,9169 & $>99,9$ & 0,9243 & $>99,9$ \\
\hline $\mathrm{MgO}$ & 0,9264 & $>99,9$ & 0,9267 & $>99,9$ \\
\hline $\mathrm{CaO}$ & 0,9655 & $>99,9$ & 0,9751 & $>99,9$ \\
\hline $\mathrm{Na}_{2} \mathrm{O}$ & 0,6248 & $90-95$ & 0,7344 & $95-99$ \\
\hline $\mathrm{K}_{2} \mathrm{O}$ & 0,5949 & $90-95$ & 0,6692 & $95-99$ \\
\hline \multirow[t]{2}{*}{$\mathrm{TiO}_{2}$} & 0,8545 & $99-99,9$ & 0,8552 & $99-99,9$ \\
\hline & \multicolumn{4}{|c|}{$\mathrm{n}=10$ amostras } \\
\hline
\end{tabular}

\begin{tabular}{c|c|c|c|c}
\hline \multicolumn{5}{c}{ Elementos traços } \\
\hline & \multicolumn{3}{c}{ Linear } & \multicolumn{2}{c}{ Polinômio } \\
\hline & $\mathrm{R}^{2}$ & \% Significância & $\mathrm{R}^{2}$ & \% Significância \\
\hline $\mathrm{Co}$ & 0,8322 & $99-99,9$ & 0,8503 & $99-99,9$ \\
\hline $\mathrm{V}$ & 0,8873 & $>99,9$ & 0,894 & $>99,9$ \\
\hline $\mathrm{Zr}$ & 0,3868 & $<80$ & 0,3868 & $<80$ \\
\hline $\mathrm{Nb}$ & 0,657 & $95-99,9$ & 0,6925 & $95-99,9$ \\
\hline $\mathrm{Rb}$ & 0,0033 & $<<80$ & 0,0052 & $<<80$ \\
\hline $\mathrm{Ba}$ & 0,4864 & $80-90$ & 0,4904 & $80-90$ \\
\hline & \multicolumn{5}{c}{$\mathrm{n}=10$ amostras } \\
\hline
\end{tabular}

fracionante. Entretanto, o baixo nível de significância das correlações testadas para $\mathrm{Zr}, \mathrm{Rb}$ e $\mathrm{Ba}$ (Tab. 3) pode ser causado por possível falta de cogeneticidade entre algumas amostras, ou até mesmo por processos de alteração a que $\mathrm{Rb}$ e Ba são susceptíveis.

Geoquímica dos elementos terras raras Apesar dos elementos maiores anteriormente estudados revelarem a existência de, pelo menos, dois agrupamentos calcioalcalinos (um de médio a alto-K e outro de alto-K) para os ortognaisses estudados, o comportamento dos elementos traços, incluindo os ETR, têm sido amplamente utilizado no estudo petrogenético.

Investigações do comportamento das TR durante o metamorfismo (Cullers et al., 1974; Muecke et al., 1979) indicam que, embora já se tenha observado mobilidades das TR durante eventos metassomáticos, geralmente há pouca modificação dos padrões de TR durante o evento metamórfico, o que permite usá-los no estudo do protólito.

.Tendo em vista que as rochas estudadas não apresentam allanita e granada, minerais que retém respectivamente $\mathrm{La}$ e $\mathrm{Yb}$, e não há qualquer evidência que leve a considerar que estes minerais estiveram presentes no protólito, os mesmos são considerados como incom- patíveis e, portanto, a razão $(\mathrm{La} / \mathrm{Yb})_{\mathrm{N}}$ foi selecionada para o estudo de cogeneticidade. As razões entre elementos incompatíveis não variam substancialmente em processo de cristalização fracionada, sendo esperadas variações em até 1,5 vezes dentre rochas cogenéticas (Cox et al., 1979).

Em uma tentativa de correlação entre os valores de $\mathrm{SiO}_{2}$ e a razão $(\mathrm{La} / \mathrm{Yb})_{\mathrm{N}}$ para o conjunto das amostras, foi constatado que o aumento de $\mathrm{SiO}_{2}$ (que expressa a diferenciação magmática em suítes granitóides) não corresponde a um aumento ou diminuição de $(\mathrm{La} / \mathrm{Yb})_{\mathrm{N}}$. Essa falta de correlação indica que nem todas as amostras do CRL são cogenéticas.

Em termos de $(\mathrm{La} / \mathrm{Yb})_{\mathrm{N}}$ a análise da razão permite reconhecer 4 grupos distintos (Fig. 6), cujas características são:

GRUPO 1 Constituído por duas amostras (uma de hornblenda-biotita gnaisse e outra de biotita gnaisse), tem teores relativamente baixos de $\mathrm{SiO}_{2}(61,11$ e 67,91$)$ e padrões ETR pouco fracionados, com $(\mathrm{La} / \mathrm{Yb})_{\mathrm{N}}$ variando em torno de uma média de 7,27. Anomalias de Eu são ligeira a fracamente negativas $\left(\mathrm{Eu} / \mathrm{Eu}^{*}: 0,96-\right.$ $0,79)$. Apresenta leve enriquecimento de TRL ( $\mathrm{La} / \mathrm{Sm})$ ${ }_{\mathrm{N}}=3,65-4,91$ e padrão subhorizontal de terras raras pesadas $(\mathrm{TRP})(\mathrm{Sm} / \mathrm{Lu})_{\mathrm{N}}=1,38-2,31$ (Fig. 6a).

GRUPO 2 Constituído por duas amostras de hornblenda-biotita gnaisse e duas de leucognaisse, tem $\mathrm{SiO}_{2}$ variando de $62,25 \%$ a $74,26 \%$ e apresenta fracionamento moderado, com $(\mathrm{La} / \mathrm{Yb})_{\mathrm{N}}$ variando entre 14,35 e 20,36 , ficando a média em 14,85. Anomalia de Eu é, em geral, ligeiramente negativa (Eu/Eu*: 0,82-0,97), porém apresenta-se mais pronunciada na amostra menos ácida (Eu/Eu*: 0,54) (Fig. 6b). Apresenta o padrão TRL levemente enriquecido $(\mathrm{La} / \mathrm{Sm})_{\mathrm{N}}=4,76-5,32$ e padrão subhorizontal para as TRP $(\mathrm{Sm} / \mathrm{Lu})_{\mathrm{N}}=2,29-4,84$.

GRUPO3 Constituído por uma amostra de biotita gnaisse e duas de leucognaisse, tem $\mathrm{SiO}_{2}$ variando de $64,82 \%$ a $71,44 \%$ e padrões de ETR mais fracionados, com $(\mathrm{La} /$ $\mathrm{Yb})_{\mathrm{N}}$ variando entre 46,97 e 62,64, ficando a média em 55,69. As anomalias de Eu, quando presentes, são ligeira a fracamente negativas (Eu/Eu*: 0,74-0,94) (Fig. 6c). Apresenta TRL variando com razão $(\mathrm{La} / \mathrm{Sm})_{\mathrm{N}}$ de 6,42 a 10,67 e TRP com razão $(\mathrm{Sm} / \mathrm{Lu})_{\mathrm{N}}$ de 4,91 a 11,81.

GRUPO 4 Representado por apenas uma amostra de hornblenda-biotita gnaisse, cujo padrão de ETR mostra-se bastante fracionado, com razão $(\mathrm{La} / \mathrm{Yb})_{N}$ igual a 103,24 (Fig. 6d). Esta amostra apresenta anomalia de Eu ligeiramente negativa $\left(\mathrm{Eu} / \mathrm{Eu}^{*}: 0,82\right)$ e razão TRL $(\mathrm{La} / \mathrm{Sm})_{\mathrm{N}}$ a 9,23 e TRP $(\mathrm{Sm} / \mathrm{Lu})_{\mathrm{N}}$ a 12,92 .

Com base na abordagem dos elementos terras raras, podemos considerar que cada um desses agrupamentos pode representar um conjunto de rochas relacionadas por processo evolutivo (cristalização fracionada ou fusão parcial sem mudança na assembléia fracionante/resíduo). Para associar estes grupos a possíveis suítes é necessário um maior número de amostras e uma abordagem meto- 


\section{GRUPO 1}

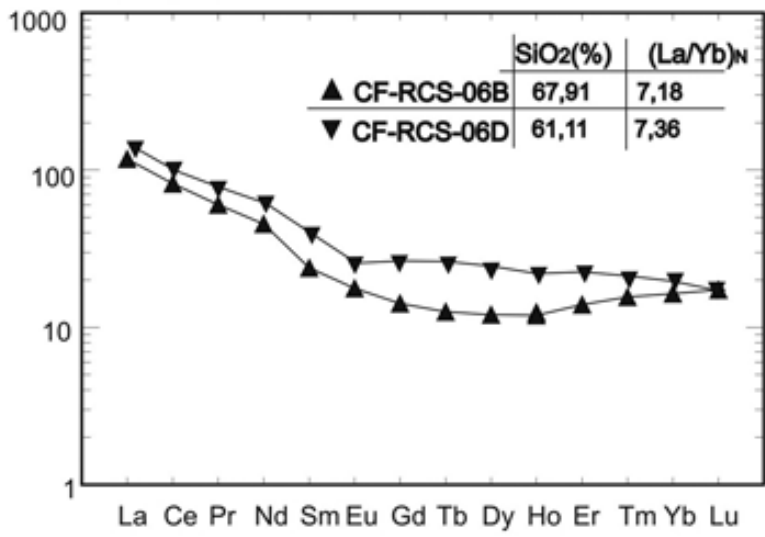

La Ce Pr Nd SmEu Gd Tb Dy Ho Er Tm Yb Lu

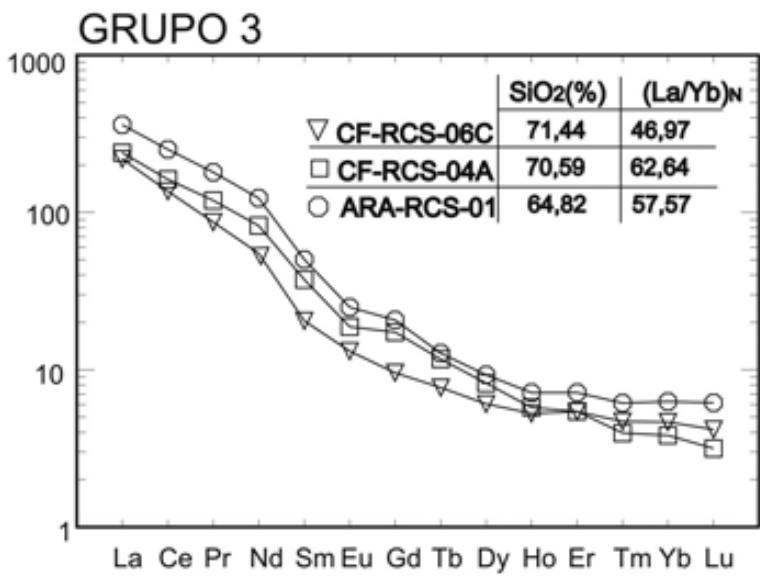

GRUPO 2

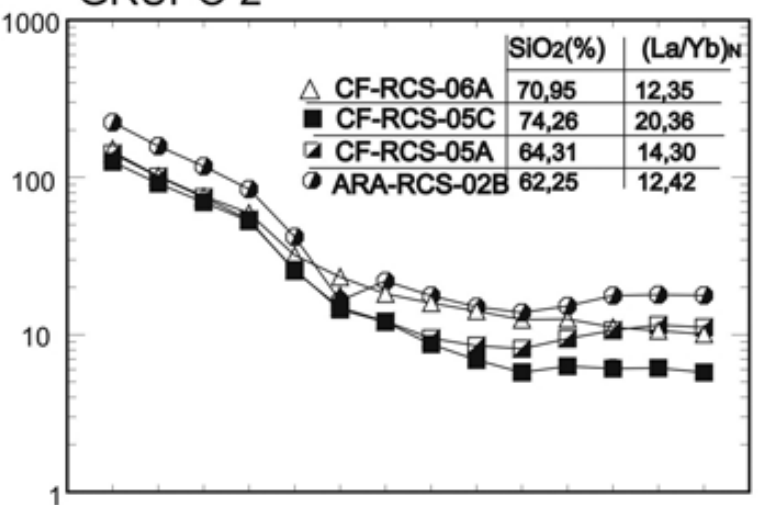

La Ce Pr Nd SmEu Gd Tb Dy Ho Er Tm Yb Lu GRUPO 4

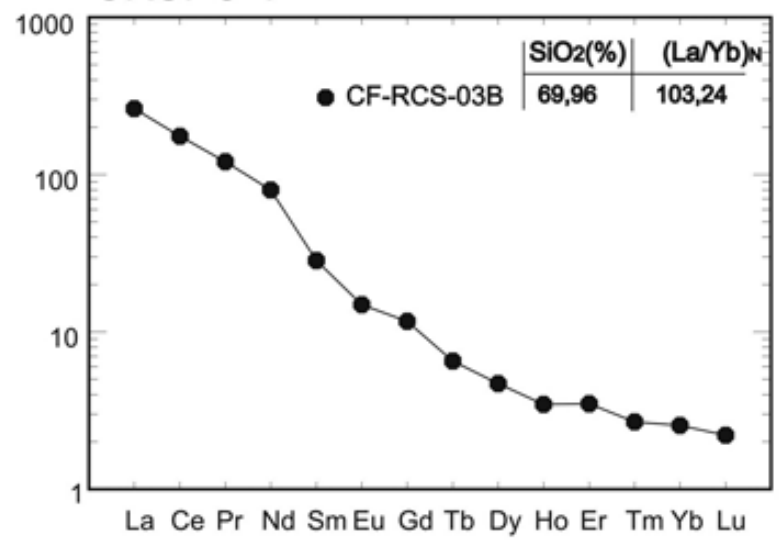

Figura 6 - Padrões de distribuição de ETR normalizados pelo condrito de Boynton (1984) para os ortognaisses do Complexo Região dos Lagos: (A) grupo 1; (B) grupo 2; (C) grupo 3 e (D) grupo 4.

dológica por meio de modelagem petrogenética.

AMBIENTES GEOTECTÔNICOS DO COMPLEXO REGIÃO DOS LAGOS Diagramas de discriminação de ambientes tectônicos têm sido utilizados com cautela para rochas précambrianas, uma vez que foram elaborados com base em eventos do Fanerozóico. Para estudar o conjunto de ortognaisses do Complexo Região dos Lagos, foram utilizados os diagramas de Pearce et al. (1984) e Harris et al. (1986). A análise dos diagramas (Fig. 7A) mostra a os quatro grupos aqui definidos ocupam predominantemente o campo de granitos de arco vulcânico. No diagrama triangular de Harris et al. (1986), observa-se que cada um dos grupos ocupa uma posição distinta no diagrama, delineando um trend em direção ao campo dos granitos intra-placa que acompanha uma diminuição no grau de fracionamento dos elementos terras raras (do grupo 4, mais fracionado, ao grupo 1, menos fracionado). Esta tendência também pode ser verificada no diagrama de Pearce et al.(1984) (Fig. 7B). As correlações e tendência observadas sugerem que os ortognaisses do Complexo Região dos Lagos formaram-se em ambiente de arco magmático e, ainda que de forma inconclusiva, devido ao número reduzido de amostras, uma evolução natural de amadurecimento deste arco.
COMPARAÇÃO COM ASSINATURAS GEOQUÍMICAS DE AMBIENTES MODERNOS A comparação das assinaturas geoquímicas das amostras com padrões de mesma ambientação, normalizados pelo granito de crista oceânica (ORG) de Pearce et al. (1984), nos revela uma grande semelhança entre os granitóides do CRL e o granito de arco vulcânico do Chile (Fig. 8).

Para os regimes tectônicos atuais, esse tipo de magmatismo calcioalcalino está fortemente relacionado a ambientes tectônicos compressivos, desenvolvidos em arcos maduros de margens continentais ativas. Segundo Pearce et al. (op cit), granitos calcioalcalinos de alto-K e séries shoshoníticas de margem continental ativa plotam predominantemente nos campos de qtz-monzonito, granodiorito e granito, relacionado ao diagrama de Streickeisen (1976), tendo biotita e hornblenda como minerais ferromagnesianos dominantes. Todas essas características são observadas nos ortognaisses do CRL.

CONCLUSÃO O Complexo Região dos Lagos inclui ortognaisses pertencentes à série calcioalcalina. Quatro grupos de rochas são sugeridos com base nos valores das razões $(\mathrm{La} / \mathrm{Yb})_{\mathrm{N}}$ : Grupo 1 - pouco fracionado e razão $(\mathrm{La} / \mathrm{Yb})_{\mathrm{N}}$ a 7,27 em média; Grupo 2 - fracionamen- 


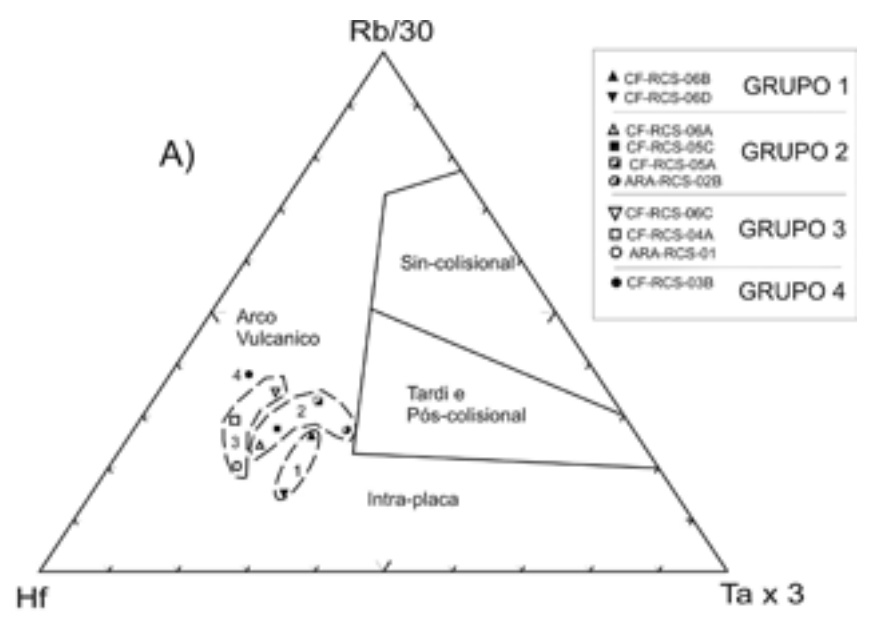

B)

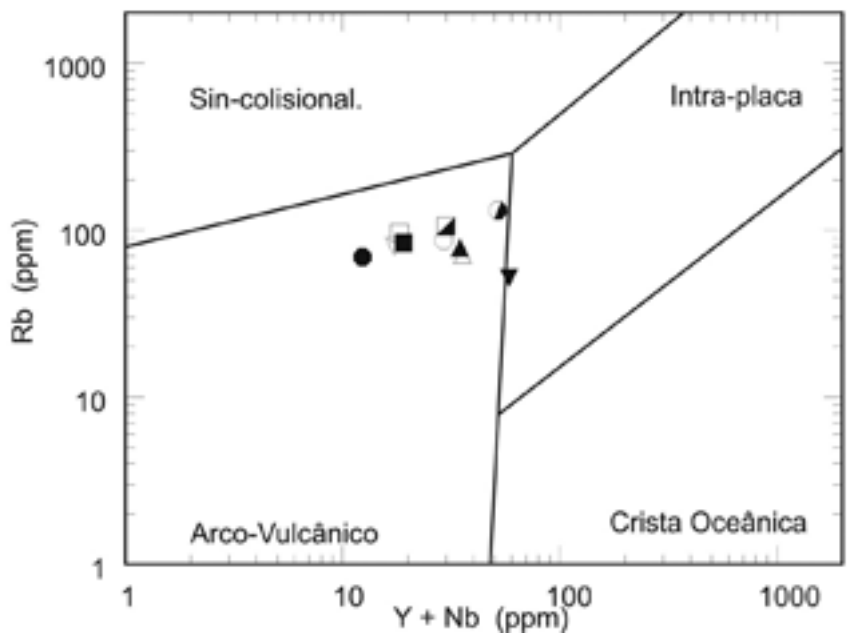

Figura 7 - Diagramas discriminantes de ambientes formadores de granito para os ortognaisses do Complexo Região dos Lagos: (a)Diagrama triangular Hf-Rb/30-Ta x3 (Harris et al. 1986) ; (b) Rb-(Y+Nb) (Pearce et al.,1984).

to moderado, com $(\mathrm{La} / \mathrm{Yb})_{\mathrm{N}}$ a 14,85 em média; Grupo 3 - com padrões de ETR mais fracionados, e razão $(\mathrm{La} /$ $\mathrm{Yb})_{\mathrm{N}}$ a 55,69 em média; e Grupo 4 - bastante fracionado, com razão $(\mathrm{La} / \mathrm{Yb})_{\mathrm{N}}$ igual a 103,24.

Nota-se ainda que os subtipos de gnaisses discriminados por critérios petrográficos distribuemse aleatoriamente por esses quatro grupos, ou seja, cada um destes grupos é litologicamente heterogêneo Quanto à ambientação tectônica, os ortognaisses aqui estudados apresentam assinaturas geoquímicas similares aos granitóides cálcio-alcalinos gerados em ambiente de arco-continental maduro, como os granitos do Chile referidos por Pearce et al. (1984). Alguns trends direcionados para o campo dos granitos intra-placa nos diagramas classificatórios sugerem uma evolução natural de amadurecimento deste arco magmático, gerado durante o Paleoproterozóico.

Agradecimentos Aos pesquisadores do Grupo de Pesquisa em Geotectônica (TEKTOS) pelo apoio nas diversas etapas deste trabalho. A FAPERJ (Processo E-26 /171.344/01-APQ1) pelo auxílio financeiro. A FAPERJ pela concessão da bolsa de mestrado ao primeiro autor.

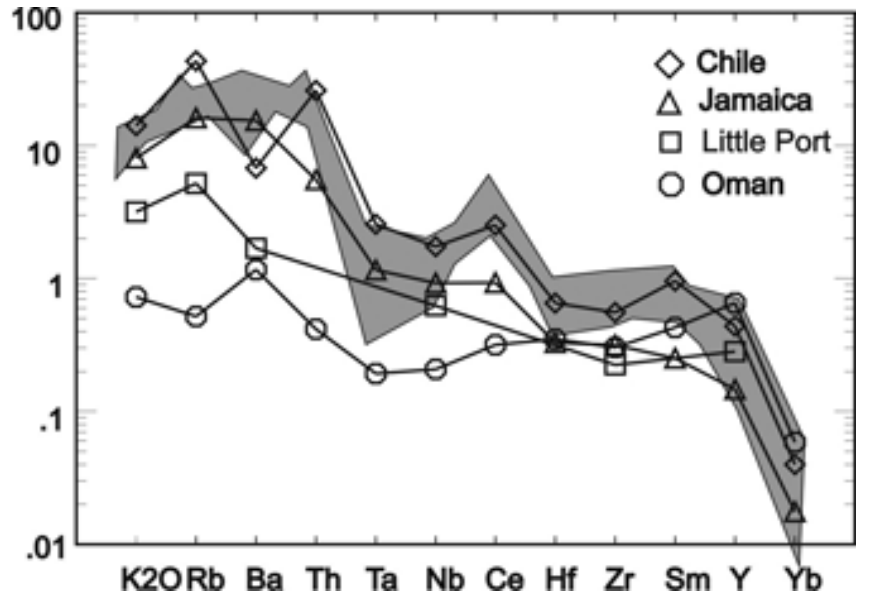

Figura 8 - Diagrama de variação multi-elementar normalisados por ORG segundo Pearce et al. (1984) para os ortognaisses do Complexo Região dos Lagos (campo hachurado), comparados com granitos de arco vulcânico modernos.

\section{Referências}

Almeida F.F.M de. 1967. Origem e Evolução da Plataforma Brasileira. Boletim da Divisão de Geologia Mineral. DNPM, Rio de Janeiro, 241:1-36.

Almeida F.F.M. de. 1969. Diferenciação Tectônica da Plataforma Brasileira In: SBG, Congresso Brasileiro de Geologia, 23, Salvador, Anais, p.29-46.

Almeida J.C.H., Tupinambá M., Heilbron M., Trouw R. 1998. Geometric and kinematic analysis at the Central Tectonic Boundary of the Ribeira belt, Southeastern Brazil, In: SBG, Congresso Brasileiro Geologia, 39,
Belo Horizonte, Anais, p. 32.

Boynton W.R. 1984. Cosmochemistry of the rare earth elements meteorite studies. In: Henderson P. (ed). Rare Earth Element Geochemistry. Amsterdan, Elsevier, p. 63-114.

Brito Neves B.B. \& Cordani U.G. 1991. Tectonic Evolution of South America during the Late Proterozoic. Precambrian Research, 53:23-40.

Cordani U.G., Melcher G.C., Almeida F.F.M. de. 1967. Outline of Precambrian Geochronology of South America. 
Canadian Journal of Earth Science, 5:629-632.

Cordani U.G., Delhal L., Ledente O. 1973. Orogéneses Superposées dans le Precambrien du Brésil SudOriental (États de Rio de Janeiro et de Minas Gerais). Revista Brasileira de Geociênicas, 3(1):1-22.

Cox K.G., Bell J.D., Pankhurst R.T. 1979. The interpretation of the igneous rocks. Univ. Chicago Press, 450p.

Cullers R.L., Yeh L.T., Chaudhury S.C.V. 1974. Rare earth elements in Silurian pelitic schists from NW marine. Geochim. Cosmchim. Acta, 38:389-400.

Fonseca A.C. 1993. Esboço Geocronológico da Região de Cabo Frio, Estado do Rio de Janeiro. Tese de Doutoramento, Instituto de Geociências, Universidade de São Paulo, 186p.

Fonseca M.J.C. 1989. O Cinturão Ribeira e o Bloco Cabo Frio. In: SBG, Simp. Geol. Sudeste, 1, Atas, p.132-133.

Fonseca M.J.C, Heilbron M., Chrispim S. 1984. Geologia Estrutural da Área de Cabo Frio e Armação de Búzios. In: Cong. Bras. Geol., 33, Rio de Janeiro, Anais, p. 53935407.

Fonseca M.J.G. 1998. Mapa Geológico do Estado do Rio de Janeiro, escala 1:400.000. Brasília, DNPM, Texto explicativo, 141p., mapa.

Harris N.B.W., Pearce J.A., Tindle A.G. 1986. Geochemical characteristics of collision-zone magmatism. In: Coward M.P. \& Ries A.C. (eds.) Collision Tectonics. Geological Society Special Publication, 19:67-81.

Heilbron M., Chrispim S.J., Alves R.P., Simões L.S.A. 1982. Geologia do Cabo dos Búzios, Anais da Academia Brasileira de Ciências, 54(3):553-562.

Heilbron M., Mohriak W.,Valeriano C.M., Milani E., Almeida J.C.H., Tupinambá M. 2000. From Collisional to Extension: The Roots of The Southheastern Continental Margin of Brasil. In: Mohriak W.U. \& Talwani M. (eds.) Geology \& Geophysics of Continental Margin. AGU Geophysical Monograph, p.1-32.

Heilbron M., Pedrosa-Soares AC., Campos Neto M.C., Silva L.C., Trouw R.A J., Janasi V. 2004. A Província Mantiqueira.In:Mantesso-Neto V., Bartorelli A., Carneiro C.D.R., Brito-Neves B.B. (eds.) Geologia do Continente Sul-Americano: Evolução da Obra de Fernando Flávio Marques de Almeida. São Paulo, Beca, p.203-234.

Irvine T.N. \& Baragar W.R.A. 1971. A guide to the chemical classification of the common volcanica rocks. Can. Jour. Earth Science, 8:523-548.

Le Maitre R.W. 1989. The chemical variability of sun common igneous rocks. J. Petrol., 17:589-537.

Maniar P.D. \& Piccoli P.M. 1989. Tectonic discrimination of granitoides. Geol. Society of Am. Bull, 101:635-643.

Muecke G.K., Pride C., Sarkar P. 1979. Rare earth element geochemistry of regional metamorphic rocks. Phys. Chem. Earth, 11:449-464.
Pearce J.A., Harris B.W., Tindle A.G. 1984. Trace element discrimination diagrams for the tectonic interpretation of granitic rocks. J. Petrol., 25:956-983.

Reis A.P., Nunes H.H.R., Chiavegatto J.R.S., Lima P.R.A., Rocha R.L.S. 1980. Projeto Carta Geológica do Estado do Rio de Janeiro. Geologia e Recursos Minerais das Folhas de Cabo Frio e Farol do Cabo. Niterói. DRM. (inédito). In: Ferrari A.L., Brenner T.L., Dalcolmo M.T., Nunes H.R.C. 1982. O Pré-Cambriano das Folhas de Itaboraí, Maricá, Saquarema e Baía da Guanabara. Cong. Bras. Geol., 32, Salvador, Anais, 1:103-114.

Schmitt R.S. 2001. Orogenia Búzios - Um evento tectonometamórfico cambro-ordoviciano caracterizado no Domínio Tectônico de Cabo Frio, Faixa Ribeira - sudeste do Brasil. Tese de Doutoramento, Instituto de Geociências, Universidade Federal do Rio de Janeiro, 273p.

Schmitt R.S., Trouw R.A.J., Van Schmus W.R. 1999. The characterization of a Cambrian $(\sim 520 \mathrm{Ma})$ tectonometamorphic event in the coastal domain of the Ribeira Belt (SE BRAZIL) - using U/Pb in syntectonic veins. In: South American Symposium on Isotope Geology, 2, Villa Carlos Paz, Córdoba, Argentina. Special Volume of Expanded Abstracts, p. 363-366.

Schmitt R.S., Trouw R.A.J., Van Schmus W.R., Pimentel M.M. 2004. Late amalgamation in the central part of Western Gondwana: new geochronological data and the characterization of a Cambrian collisional orogeny in the Ribeira belt (SE Brazil). Precambrian Research, 133:2961.

Streckeisen A. 1976. To each plutonic rocks its proper name. Earth Science Reviews, 12:1-33.

Tupinambá M., Teixeira W., Heilbron M. 1998. The Pan-African/Brasiliano Arc-related Magmatism at the Costeiro Domain of the Ribeira belt, Southeastern Brazil. In: International Conference on Precambrian and Craton Tectonics, International Conference on Basement Tectonics, 14, Abstracts, p. 12-14.

TupinambáM., TeixeiraW.,Heilbron M.2000.Neoproterozoic western Gondwana assembly and subduction-related plutonism: the role of the Rio Negro Complex in the Ribeira Belt, South-eastern Brazil. Revista Brasileira de Geociencias, 30(1):7-11.

Zimbres E., Kawashita K., Van Schmus W.R. 1990. Evidências de um núcleo transamazônico na região de Cabo Frio, RJ e sua conexão com o Cráton de Angola. In: SBG/RN, Congresso Brasileiro de Geologia, 36, Natal, Anais, 6:2735-2743.

Manuscrito ID 9078

Submetido em 13 de setembro de 2007 Aceito em 20 de setembro de 2008 Sistema eletrônico de submissão 